\title{
The Effect of Ionic Liquids on the Corrosion Inhibition of Copper in Acidic Chloride Solutions
}

\author{
M. Scendo and J. Uznanska \\ Institute of Chemistry, UJK Kielce, ul. Swietokrzyska 15G, 25406 Kielce, Poland \\ Correspondence should be addressed to M. Scendo, scendo@ujk.edu.pl \\ Received 19 August 2010; Accepted 21 December 2010 \\ Academic Editor: Willem J. Quadakkers
}

Copyright ( $) 2011$ M. Scendo and J. Uznanska. This is an open access article distributed under the Creative Commons Attribution License, which permits unrestricted use, distribution, and reproduction in any medium, provided the original work is properly cited.

The influence of the concentration of the 1-Butyl-3-methylimidazolium chloride (BMIMCl) and 1-Butyl-3-methylimidazolium bromide (BMIMBr) as ionic liquids (ILs) on the corrosion inhibition of copper in $1.0 \mathrm{M} \mathrm{Cl}^{-}$solutions of pH 1.0 was studied. The investigation involved electrochemical polarization methods as well as electrochemical quartz crystal microbalance (EQCM) technique and scanning electron microscopy (SEM). The inhibition efficiency increases with an increase in the concentration of $\mathrm{BMIMCl}$ and BMIMBr. Adherent layers of inhibitors were postulated to account for the protective effect. Both of the compounds act as a mixed-type inhibitor. The values of standard free energy of adsorption suggest the chemical adsorption $\mathrm{BMIMCl}$ and BMIMBr on the copper surface.

\section{Introduction}

Copper and its alloys are used extensively in many kinds of chemical equipment. Several corrosion inhibitors for copper and its alloys have been known and applied for corrosion protection. The inhibition properties of triazole, imidazole, and thiazole derivatives in the corrosion of copper have been studied [1-4]. Some heterocyclic compounds containing a mercapto group have been developed as copper corrosion inhibitors. These compounds include 2-mercaptobenzothiazole [5], 2,4-dimercaptopyrimidine [6], 2-amino-5-mercaptothiadzole, 2-mercaptothiazoline [7], potassium ethyl xanthate [8-11], and indole and derivatives [12]. Among the numerous organic compounds tested and industrially applied as corrosion inhibitors, nontoxic are far more strategic now than in the recent past. These compounds include such amino acids [13-15] and derivatives as cysteine [16].

In the past two decades, the research in the field of green corrosion inhibitors has been addressed toward the goal of using cheap effective molecules at low or zero environmental impact. These compounds include purine and adenine, which have been tested for copper corrosion in chloride $[17,18]$, sulfate [19], and nitrate solutions [20].
Ionic liquids (ILs) are molten salts with melting points at or below ambient room temperature, which are composed of organic cations and various anions. Ionic liquids possess a large number of physicochemical properties [21-24], mainly, good electrical conductivity, solvent transport, and a relatively wide electrochemical window [24]. Configuration of ILs consists of an amphiphilic group with a long chain, hydrophobic tail, and a hydrophilic polar head. Usually, ILs have nitrogen, sulphur, and phosphorus as the central atoms of cations, such as imidazolium, pyrrolidinium, quaternary ammonium, pyridinium, piperidinium, sulfonium and quaternary phosphonium. Currently, functionalized IL is a very noticable topic in the field of IL research. Introducing different functional groups into cations, which provides a great deal of ILs with new structures, can markedly change the physicochemical properties of ILs, and it also affords more choices for applications of ILs in electrochemical devices.

Imidazolium compounds are reported to show corrosionresistant behavior on mild steel [25], copper [26, 27], and aluminium [28]. It was found that the action of such inhibitors depends on the specific interaction between the functional groups and the metal surface, due to the presence 


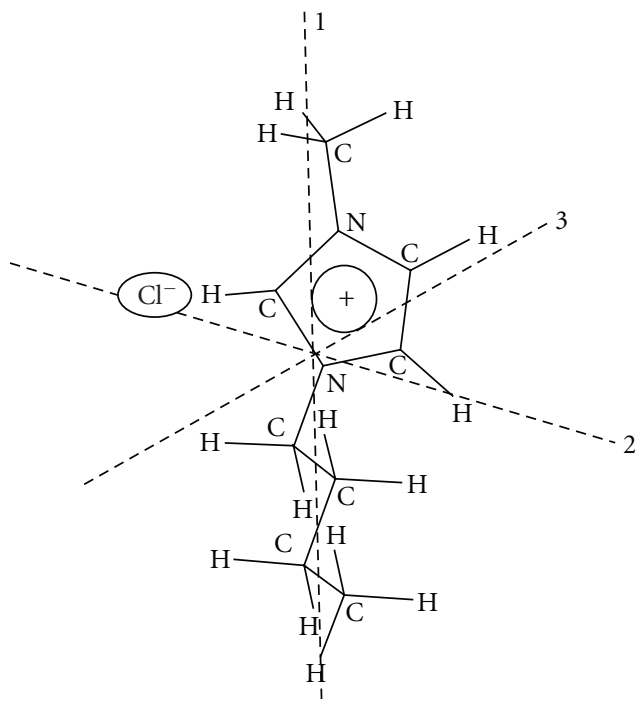

(a)

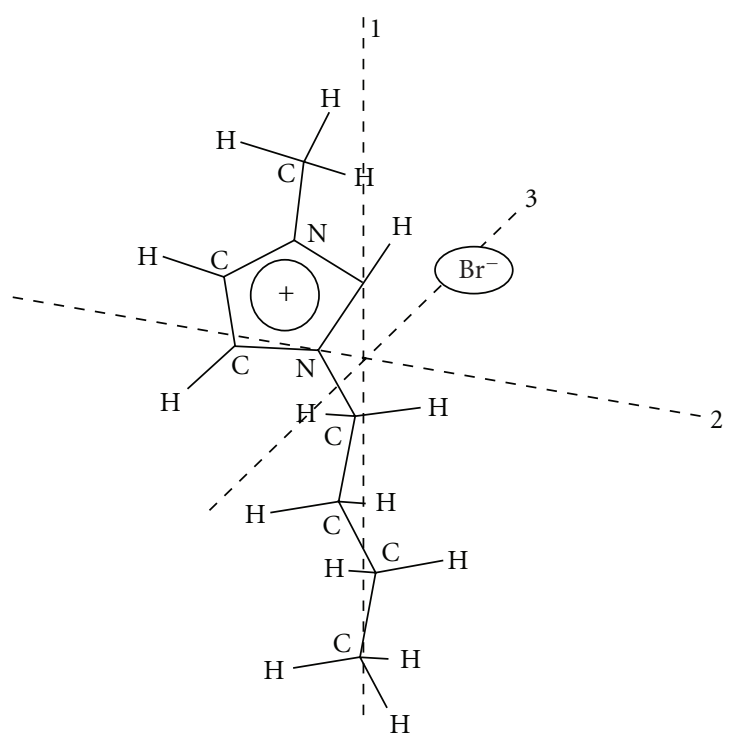

(b)

Figure 1: Molecular structures ionic liquids: (a) 1-Butyl-3-methylimidazolium chloride (BMIMCl), (b) 1-Butyl-3-methylimidazolium bromide (BMIMBr).

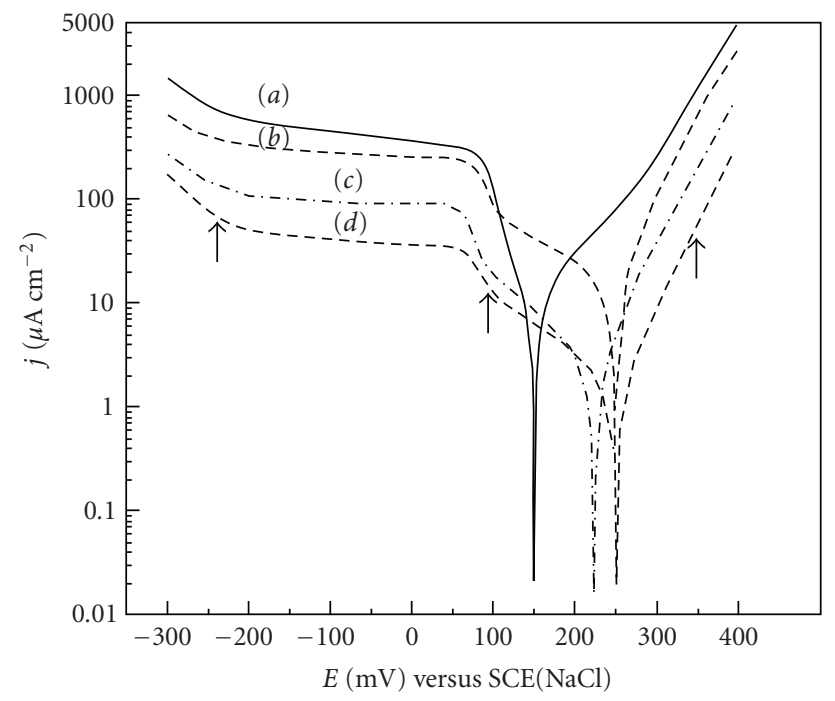

FIGURE 2: Some chosen polarization curves of copper in $1.0 \mathrm{M}$ $\mathrm{Cl}^{-}$solutions containing different concentrations of 1-Butyl-3methylimidazolium bromide: (a) 0, (b) 1.0, (c) 10.0, and (d) $50.0 \mathrm{mM}, \mathrm{pH}$ 1.0. The scan rate of $1 \mathrm{mV} \mathrm{s}^{-1}$. Arrows indicate potential for chronoamperometric measurements.

of the $-\mathrm{C}=\mathrm{N}-$ group and electronegative nitrogen in the molecule. Ionic liquids and different types of surfactants base inhibitors are well known to have a high activity in acid medium $[29,30]$ and therefore are used in oil field to minimize carbon dioxide-induced corrosion [31, 32]. Among many kinds of functionalized ionic liquids ether-functionalized ILs have been investigated intensively, and ether groups have been successfully introduced into imidazolium cations [33-39]. Shi et al. [40] have synthesized

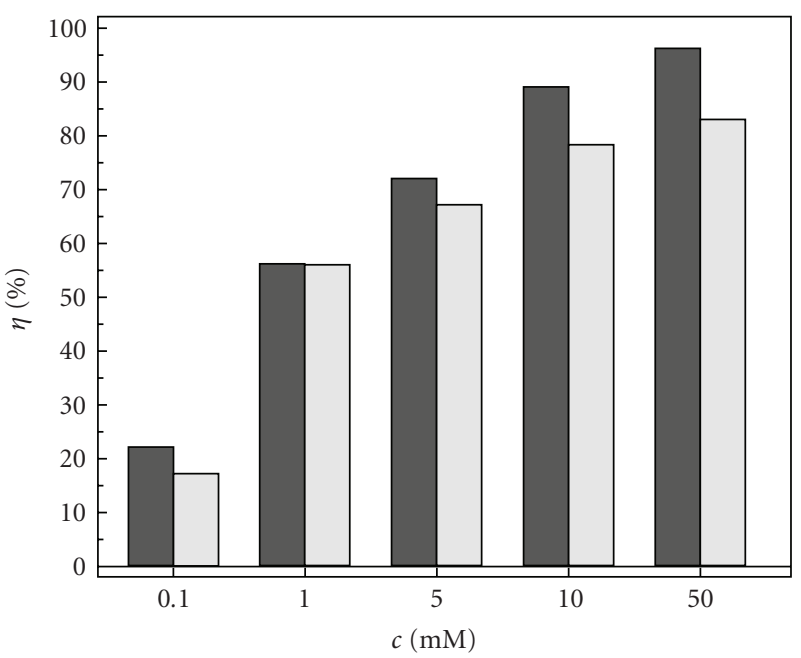

BMIMCI

$\mathrm{BMIMBr}$

FIGURE 3: Inhibition efficiency of copper in $1.0 \mathrm{M} \mathrm{Cl}^{-}$solutions with different concentrations of 1-Butyl-3-methylimidazolium chloride and 1-Butyl-3-methylimidazolium bromide.

a series of new imidazolium ionic liquids with highly pure naphthenic acids and investigated the relationship between the alkyl connecting with $\mathrm{N}_{3}$ of imidazolium ring and corrosion inhibition performance in acidic solution. The inhibition efficiency $(\eta)$ was found to increase with increasing the carbon chain length of the alkyl connecting with $\mathrm{N}_{3}$ of imidazolium ring. However, no substantial information is available on imidazolium ionic liquids using as corrosion inhibitors in acidic chloride solutions. 


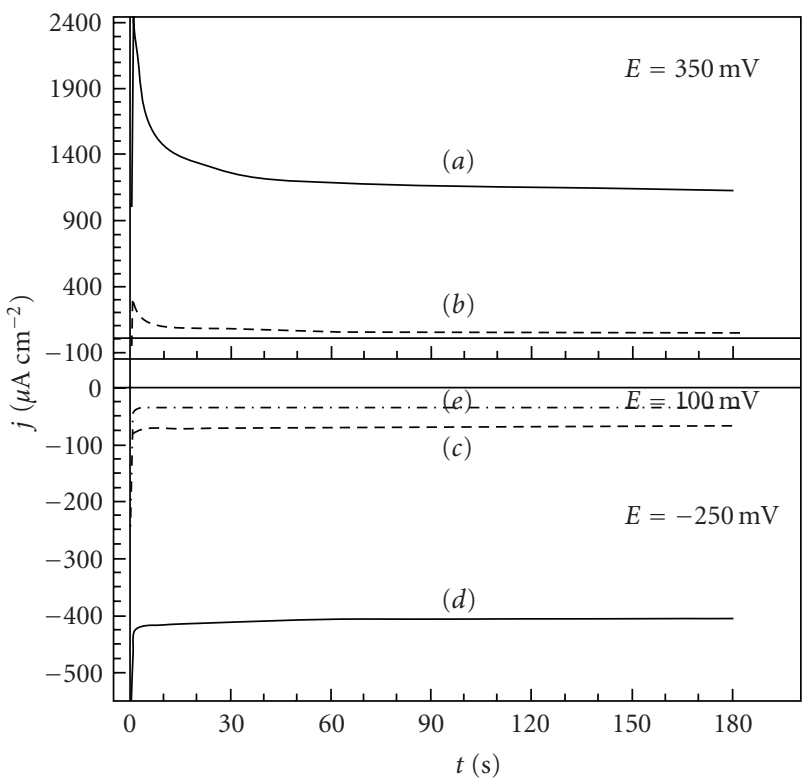

FIgure 4: Chronoamperometric curves for copper in $1.0 \mathrm{M} \mathrm{Cl}^{-}$ solutions: $(a)$ and $(d)$ without, $(b),(c)$ and $(e)$ with $50.0 \mathrm{mM} \mathrm{1-}$ Butyl-3-methylimidazolium chloride. Potential electrode: $(a),(b)$ $+350,(c),(d)-250$, and $(e)+100 \mathrm{mV}$.

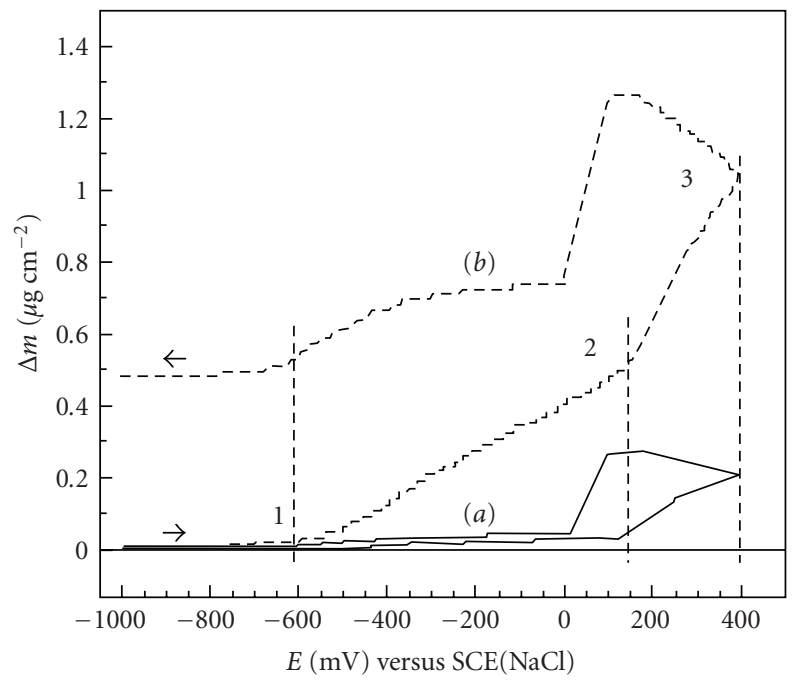

Figure 5: Mass change of copper electrode with potential in $1.0 \mathrm{M} \mathrm{Cl}^{-}$solutions: (a) without and (b) with $50.0 \mathrm{mM} \mathrm{1-Butyl-}$ 3 -methylimidazolium bromide. The scan rate of $1 \mathrm{mV} \mathrm{s}^{-1}$. Arrows indicate of direction of potential scanning.

The present work describes a study of the corrosion of copper in $1.0 \mathrm{M} \mathrm{Cl}^{-}$solutions of $\mathrm{pH} 1.0$ without and with different concentrations of 1-Butyl-3-methylimidazolium chloride (BMIMCl) or 1-Butyl-3-methylimidazolium bromide (BMIMBr), based on copper stationary disk electrode (SDE) voltammetry measurements as well as quartz crystal microbalance (EQCM) and scanning electron microscopy (SEM).

\section{Experimental}

2.1. Solutions. 1-Butyl-3-methylimidazolium chloride, $\mathrm{C}_{8} \mathrm{H}_{15} \mathrm{ClN}_{2}$ (BMIMCl) and 1-Butyl-3-methylimidazolium bromide, $\mathrm{C}_{8} \mathrm{H}_{15} \mathrm{BrN}_{2}$ (BMIMBr) ( $>99.8 \%$ ) were purchased from Fluka. The molecular structures of compounds are shown in Figure 1. It is worth to notice that both BMIMCl and $\mathrm{BMIMBr}$ are not flat molecules. $\mathrm{BMIMCl}$ and $\mathrm{BMIMBr}$ are stable in air, water, and in the majority of organic solvents. Both compounds are enough well solvable in water. The solutions were prepared using analytical grade reagents and bidistilled water (resistivity $12 \mathrm{M} \Omega \mathrm{cm}$ ). BMIMCl and $\mathrm{BMIMBr}$ were dissolved at concentrations in the range of $0.1-50.0 \mathrm{mM}$. All studied solutions contained $1.0 \mathrm{M} \mathrm{Cl}^{-}$of $\mathrm{pH}$ 1.0. The solutions were prepared through the mixing up of suitable quantities of $\mathrm{NaCl}$ and $\mathrm{HCl}$ for all experiments were used a naturally aerated solutions.

2.2. Electrochemical Measurements. Electrochemical experiments were carried out in a classical three-electrode glass cell. The cell was open to air. The working electrode $(W)$ was home made stationary disk electrode of the Specpure copper (Johnson Matthey Chemicals Ltd.) with $r=0.240 \mathrm{~cm}, A=$ $0.181 \mathrm{~cm}^{2}$. Prior to each experiment, the $W$ was mechanically abraded to mirror gloss using in this aim 1000 and 2000 grade emery papers. Then electrode was washed several times on change bidistilled water and ethanol. Finally, SDE was dried using a stream of air. Such pretreatment of the disk was repeated after each voltammetric measurement. Other details were published in [12, 41-44]. All the surface area-dependent values are normalized with respect to the geometric surface area of the working electrode.

Electrode potentials were measured and reported against the external saturated calomel electrode with $\mathrm{NaCl}$ solution ( $\mathrm{SCE}(\mathrm{NaCl}))$ coupled to a fine Luggin capillary. To minimize the ohmic contribution, the capillary was kept close to the working electrode. A platinum (purity 99.99\%) wire was used as an auxiliary electrode. Auxiliary electrode was individually isolated from the test solution by glass frit.

All voltammetric experiments were performed using a Model EA9C electrochemical analyzer, controlled via Pentium computer using the software Eagraph v. 4.0. The polarization curves were obtained using the linear potential sweep (LSV) technique. Before each run, the clean copper SDE was quickly inserted into the solution and immediately cathodically polarized at $-800 \mathrm{mV}(\mathrm{SCE}(\mathrm{NaCl}))$ for $3 \mathrm{~min}$ to reduce any oxide on the copper surface. The scan started from the cathodic to the anodic direction with the scan rate of $1 \mathrm{mV} \mathrm{s}^{-1}$.

The chronoamperometric curves were recorded at the different potentials electrode in solutions without and with inhibitors. The potentials applied for the copper electrode were chosen on basis of polarization curves.

During the measurements, the solution was not stirred. Electrochemical experiments were repeated many times, until reproducible curves were received.

2.3. Electrochemical Quartz Crystal Microbalance. Electrochemical quartz crystal microbalance (EQCM) experiments 


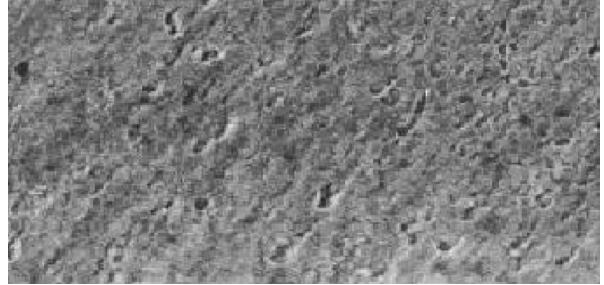

(a)

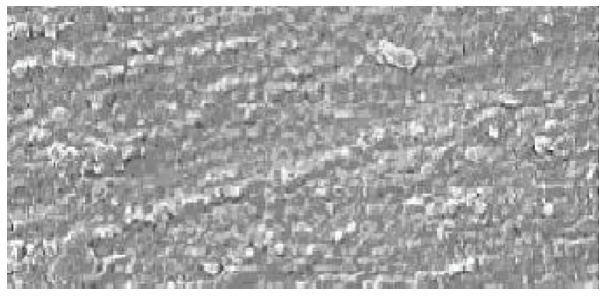

(c)

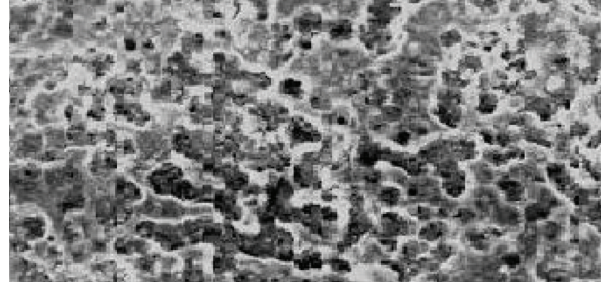

(b)

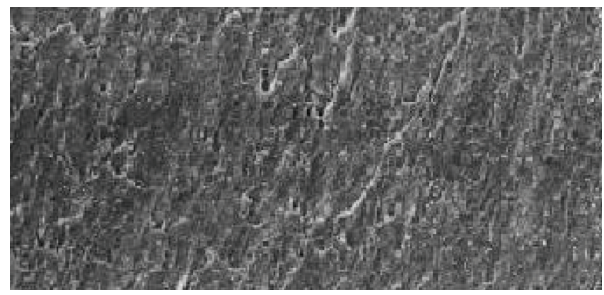

(d)

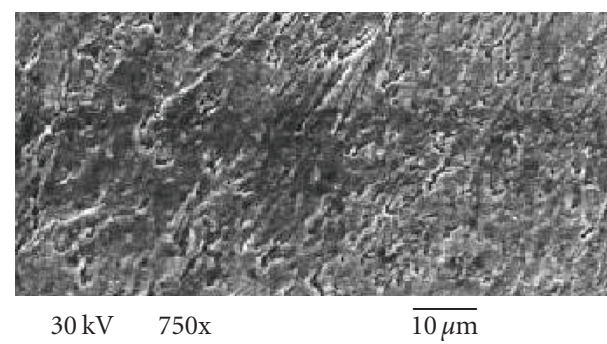

(e)

FIGURE 6: SEM micrographs of the surface of copper: (a) before, (b) after being immersed for 24 hours in $1.0 \mathrm{M} \mathrm{Cl}^{-} \mathrm{pH} 1.0$, (c) corrosive solution contained additionally $50.0 \mathrm{mM}$ of 1-Butyl-3-methylimidazolium chloride and after the removal of the inhibiting film: (d) 1-Butyl3-methylimidazolium chloride, (e) 1-Butyl-3-methylimidazolium bromide (magnification 750x).

were performed with an apparatus constructed in the Institute of Physical Chemistry, Warsaw. The quartz crystal had a geometric area of $0.432 \mathrm{~cm}^{2}$ and was operated at the fundamental frequency of $5 \mathrm{MHz}$ (refers to air). The sensitivity of the EQCM can be a few nanograms per square centimeter, which makes it an ideal equipment for corrosion studies. Other details of the EQCM system used in this study were similar to those previously described $[11,12$, 44].

Copper was galvanostatically deposited onto one surface of the crystal (resonator). The freshly deposited copper electrode was thoroughly washed with bidistilled water. Then the aggressive solution was immediately added to the cell.

2.4. Scanning Electron Microscope. A scanning electron microscope PHILIPS (XL 30) was used to study the morphology of the copper surface in the absence and presence of the inhibitor. Samples were attached on the top of an aluminum stopper by means of $3 \mathrm{M}$ carbon conductive adhesive tape (SPI).

All experiments were carried out at $25.0 \pm 0.2^{\circ} \mathrm{C}$ using an air thermostat with the forced air circulation.

\section{Results and Discussion}

3.1. Polarization Behaviour of Copper. The effect of 1-Butyl3-methylimidazolium chloride and 1-Butyl-3-methylimidazolium bromide on the corrosion reactions of copper was determined by polarization measurements. Figure 2 shows an example of polarization curves for the copper electrode in $1.0 \mathrm{M} \mathrm{Cl}^{-}$solutions of $\mathrm{pH} 1.0$ without and with different concentrations of BMIMBr. Similar curves were recorded for BMIMCl.

Regarding the mechanism of the oxygen reduction reaction on copper in acidic solutions a lot of work has been done [45-48]. The cathodic polarization curve $(a)$ may be attributed to the diffusion-controlled reduction of oxygen. It is also worth emphasizing that the curve $(a)$ includes two faintly visible waves, which do not appear for deoxidized solutions $[17,18]$. The cathodic global reaction in an aerated acidic aqueous solution could be described as follow [49-51]:

$$
\mathrm{O}_{2}+4 \mathrm{H}^{+}+4 \mathrm{e}^{-} \longleftrightarrow 2 \mathrm{H}_{2} \mathrm{O}
$$

However, the first cathodic wave is attributed to the reaction

$$
\mathrm{O}_{2}+2 \mathrm{H}^{+}+2 \mathrm{e}^{-} \longleftrightarrow \mathrm{H}_{2} \mathrm{O}_{2}
$$




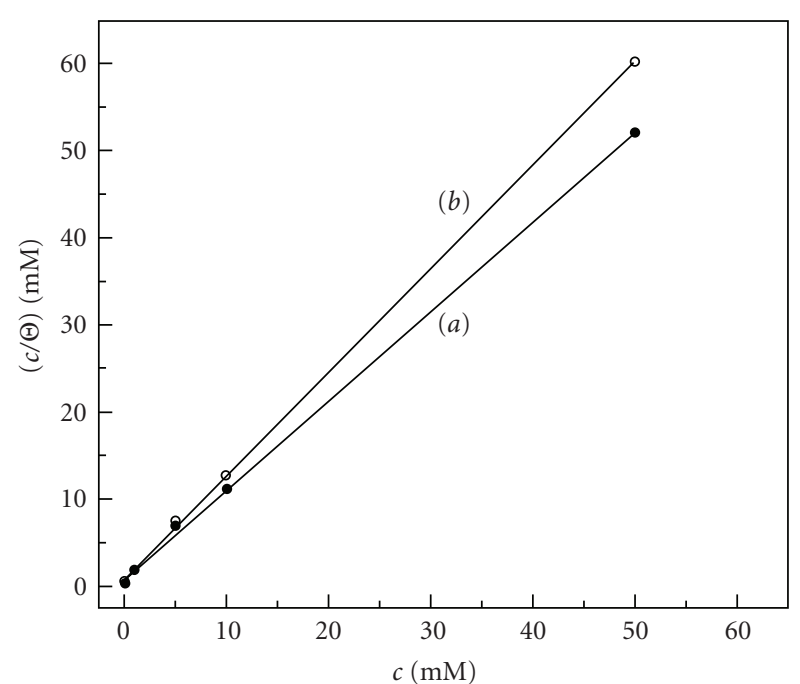

FIgURE 7: Langmuir's adsorption plots for copper in $1.0 \mathrm{M}$ $\mathrm{Cl}^{-}$solutions containing different concentrations of inhibitors: (a) 1-Butyl-3-methylimidazolium chloride and (b) 1-Butyl-3methylimidazolium bromide.

In the more negative potential of the electrode surface the next reaction occurs:

$$
\mathrm{H}_{2} \mathrm{O}_{2}+2 \mathrm{H}^{+}+2 \mathrm{e}^{-} \longleftrightarrow 2 \mathrm{H}_{2} \mathrm{O} \text {. }
$$

Furthermore, the reaction (1a) is strongly influenced by potential [50]. The cathodic parts, curves $(b)-(d)$, show that in the presence of 1-Butyl-3-methylimidazolium bromide ( similarly as in the case of 1-Butyl-3-methylimidazolium chloride) the cathodic currents decrease as the BMIMCl or BMIMBr concentrations increase. However, the curves $(b)-$ (d) split up into two waves, which correspond to reactions (1b) and (1c). As it is discussed below, this shoulder may concern to the adsorption of the BMIMCl or BMIMBr on copper surface. After crossing potential at about the $-300 \mathrm{mV},(\mathrm{SCE}(\mathrm{NaCl}))$ was observed of the growth of density of current as a result of the formation of gas hydrogen on the electrode surface.

The dissolution process of copper (anodic corrosion reaction) at low overpotentials runs according to the following steps $[15,52]$ :

$$
\begin{gathered}
\mathrm{Cu}-\mathrm{e}^{-} \longleftrightarrow \mathrm{Cu}_{\mathrm{ads}}^{+} \\
\mathrm{Cu}_{\mathrm{ads}}^{+}-\mathrm{e}^{-} \longleftrightarrow \mathrm{Cu}^{2+},
\end{gathered}
$$

where the $\mathrm{Cu}_{\mathrm{ads}}^{+}$is an adsorbed monovalent species of copper on the electrode surface.

In corrosive medium in presence of complexing ions such as $\mathrm{Cl}^{-}$the dissolution process of $\mathrm{Cu}$ proceeds via a two-step reaction mechanism $[17,18]$. During the first step, copper is ionized under the influence of $\mathrm{Cl}^{-}$ion, yielding $\mathrm{CuCl}$ adsorbed at the electrode

$$
\mathrm{Cu}+\mathrm{Cl}^{-}-\mathrm{e}^{-} \longleftrightarrow \mathrm{CuCl}_{\mathrm{ads}}
$$

This adsorbed compound dissolves by combining with another $\mathrm{Cl}^{-}$ion according to reactions

$$
\mathrm{CuCl}_{\mathrm{ads}}+\mathrm{Cl}^{-}-\mathrm{e}^{-} \longleftrightarrow \mathrm{CuCl}_{2, \text { sol }}
$$

or

$$
\mathrm{CuCl}_{\mathrm{ads}}+\mathrm{Cl}^{-} \longleftrightarrow \mathrm{CuCl}_{2, \mathrm{sol}}^{-} \text {. }
$$

Products as a result of reactions (4a) and (4b) move to bulk of solution. However, in $1.0 \mathrm{M}$, the $\mathrm{Cl}^{-}$concentration range of $\mathrm{CuCl}_{2}^{-}$is the dominant cuprous species $[10-12,53]$, while at higher concentrations the reaction is proportional to $\left[\mathrm{Cl}^{-}\right]^{x}$, where $x>2$ [54].

Figure 2 shows that the cathodic and anodic currents decrease with the increase of the concentration of BMIMBr (curves $(b)-(d))$. Probably the protonated 1-Butyl-3methylimidazolium chloride $\left[\mathrm{BMIMClH}^{+}\right]$and 1-Butyl-3methylimidazolium bromide $\left[\mathrm{BMIMBrH}^{+}\right]$molecules are electrostatically adsorbed on the cathodic sites of Cu. Cations of ILs are large; in addition, the alkyl chain covers a wide part of the copper surface [55]. However, the hydrophobic chain may be oriented horizontally or vertically to the electrode plane. The adsorption or desorption of $\mathrm{Cl}^{-}$and $\mathrm{Br}^{-}$ions occurs on the anodic sites. The adsorbed species such as $\mathrm{CuCl}_{\mathrm{ads}}$ interact with the cations of ILs to form molecular layers as a complex on the copper surface [56]. This indicates that the addition of BMIMCl and BMIMBr affects both the cathodic and anodic reactions; therefore, the compounds act as mixed-type inhibitors.

3.1.1. Corrosion Parameters. Electrochemical corrosion kinetic parameters were calculated on the basis of cathodic and anodic potential versus current characteristics in the Tafel potential region (Figure 2). The corrosion parameters such as corrosion potential $\left(E_{\text {corr }}\right)$, corrosion current density $\left(j_{\text {corr }}\right)$, cathodic $\left(b_{c}\right)$, and anodic $\left(b_{a}\right)$ Tafel slope are listed in Table 1. It is worth noticing that no definite trend was observed in the shift of the $E_{\text {corr }}$ values in the presence of various concentrations of 1-Butyl-3-methylimidazolium chloride and 1-Butyl-3-methylimidazolium bromide. This confirms earlier advanced admission that both inhibitors belong to mixed-type inhibitors. The current density (Table 1) decreased when the concentrations of BMIMCl and BMIMBr were increased. This indicates the inhibiting effect of 1-Butyl-3-methylimidazolium chloride and 1Butyl-3-methylimidazolium bromide. An increase in cathodic $\left(b_{c}\right)$ and a decrease in anodic $\left(b_{a}\right)$ Tafel slopes (Table 1) indicated a mixed cathodic and anodic effect of the inhibition on the copper corrosion mechanism. Moreover, these inhibitors cause small change in the cathodic and anodic Tafel slopes, indicating that BMIMCl and BMIMBr are first adsorbed onto copper surface and therefore impeded by merely blocking the reaction sites of copper surface without affecting the cathodic and anodic reaction mechanism [57]. Generally speaking, the inhibitor molecule blocks the active corrosion sites on the copper surface. 


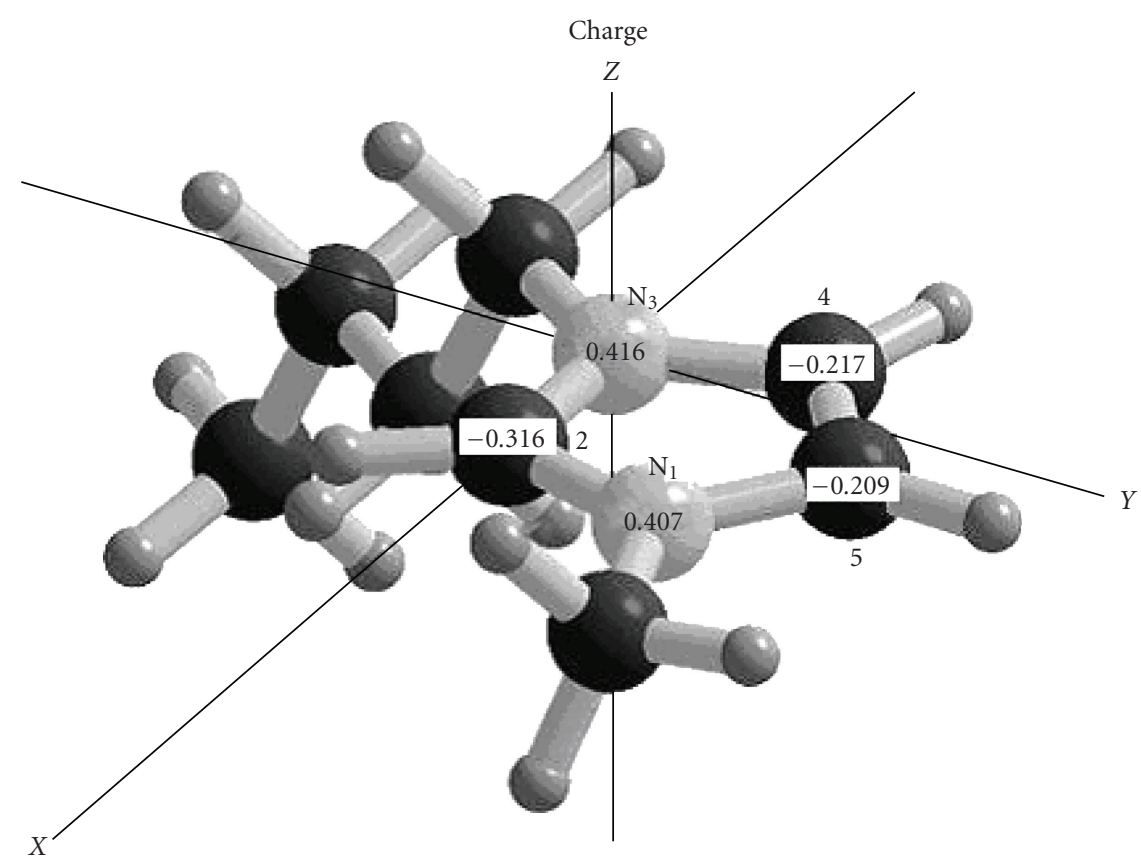

(a)

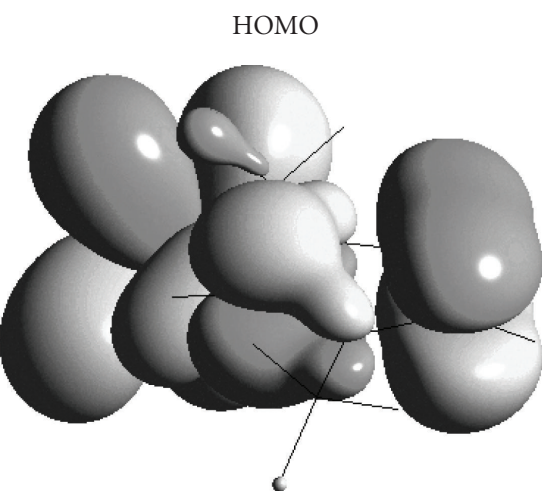

(b)

LUMO

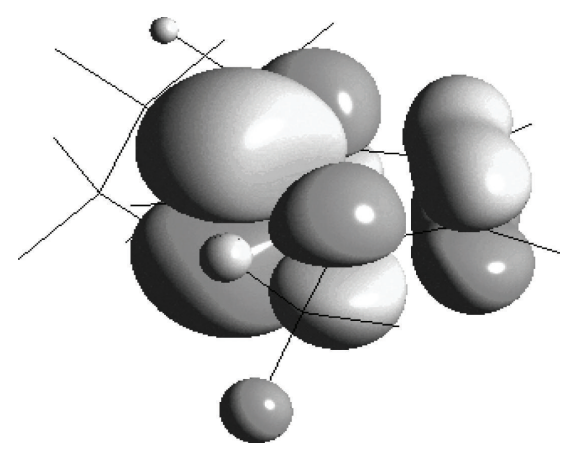

(c)

FIGURE 8: Molecular structure of 1-Butyl-3-methylimidazolium ion (the charges density distribution on nitrogen: $\mathrm{N}_{1}, \mathrm{~N}_{3}$ and carbon: $\mathrm{C}_{2}$, $\mathrm{C}_{4}, \mathrm{C}_{5}$ atoms), and molecular orbital density distribution of $\mathrm{BMIM}^{+}$; highest occupied molecular orbital (HOMO) and lowest unoccupied molecular orbital (LUMO).

3.1.2. Inhibition Efficiency. The inhibition efficiency $(\eta)$ can also be calculated from polarization tests by using the following equation $[58,59]$ :

$$
\eta(\%)=\left(\frac{j_{o}-j_{\text {corr }}}{j_{0}}\right) 100,
$$

where $j_{o}$ and $j_{\text {corr }}$ are the corrosion current densities in the absence and presence of inhibitor, respectively.

The inhibition efficiency depends on both the nature and the concentration of the investigated compounds. The calculated inhibition efficiencies are presented in Figure 3. In the presence of 1-Butyl-3-methylimidazolium chloride and 1-Butyl-3-methylimidazolium bromide, the inhibition efficiency increases with an increase in for the concentration of inhibitors. However, for concentration $50.0 \mathrm{mM}$ both inhibitors $\eta$ are the highest for 1-Butyl-3-methylimidazolium chloride. It is obvious that for higher concentration of 1Butyl-3-methylimidazolium bromide we will get a film which considerably better protects the surface of copper.

3.1.3. Corrosion Rate. The corrosion current density $\left(j_{\text {corr }}\right)$ was converted into the corrosion rate $\left(k_{r}\right)$ by using the expression [60]

$$
k_{r}\left(\frac{\mathrm{mm}}{\text { year }}\right)=3.268 \times 10^{-3}\left(\frac{j_{\mathrm{corr}} M_{\mathrm{Cu}}}{n \rho}\right),
$$

where the corrosion current density $\left(j_{\text {corr }}\right)$ should be in $\mu \mathrm{A} \mathrm{cm}^{-2}, M_{\mathrm{Cu}}$ is the molecular weight of copper, $n$ is the number of electrons transferred in the corrosion reaction, and $\rho$ is the density of $\mathrm{Cu}\left(\mathrm{g} \mathrm{cm}^{-3}\right)$.

The values of the copper corrosion rate in the absence and presence of inhibitors were calculated from (6) and 


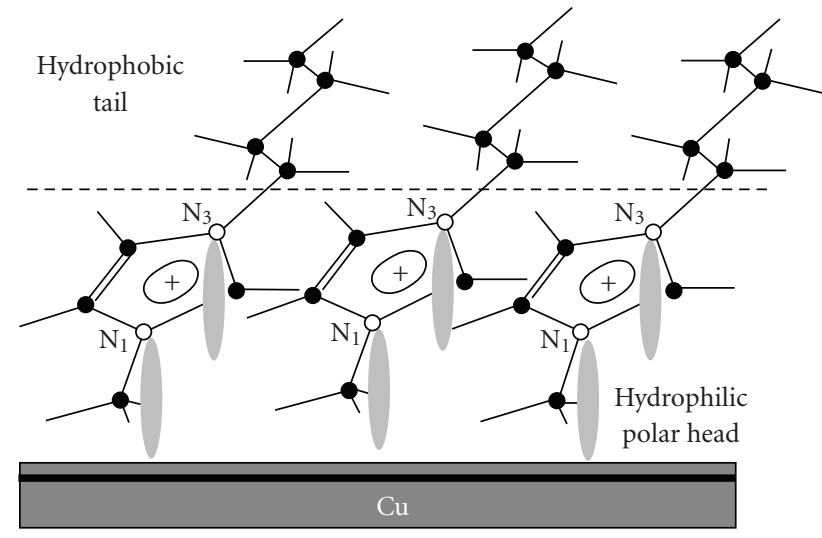

FIGURE 9: Schematic illustration of the mechanism of corrosion protection of copper by BMIMX (where $\mathrm{X}$ is the $\mathrm{Cl}^{-}$or $\mathrm{Br}^{-}$ions).

TABle 1: Corrosion parameters of copper in $1.0 \mathrm{M} \mathrm{Cl}^{-}$solutions in the absence or presence of different concentrations of 1-Butyl3-methylimidazolium chloride and 1-Butyl-3-methylimidzaolium bromide, $\mathrm{pH} 1.0$.

\begin{tabular}{lccccc}
\hline Inhibitor & $\begin{array}{l}\text { Concentration } \\
(\mathrm{mM})\end{array}$ & $\begin{array}{l}E_{\text {corr }} \\
(\mathrm{mV})\end{array}$ & $\begin{array}{l}j_{\text {corr }} \\
\left(\mu \mathrm{A} \mathrm{cm}^{-2}\right)\end{array}$ & $\begin{array}{l}-b_{c} \\
\left(\mathrm{mV} \mathrm{dec}^{-1}\right)\end{array}$ \\
\hline without & 0 & 149 & 18 & 50 & 130 \\
\hline \multirow{6}{*}{ BMIMCl } & 0.1 & 162 & 14 & 55 & 126 \\
& 1.0 & 125 & 8 & 65 & 120 \\
& 5.0 & 183 & 5 & 70 & 114 \\
& 10.0 & 207 & 2 & 75 & 110 \\
& 50.0 & 165 & 0.8 & 85 & 100 \\
\hline \multirow{5}{*}{ BMIMBr } & 0.1 & 197 & 15 & 70 & 115 \\
& 1.0 & 247 & 9 & 100 & 90 \\
& 5.0 & 248 & 6 & 110 & 80 \\
& 10.0 & 224 & 3 & 120 & 70 \\
& 50.0 & 249 & 1.4 & 140 & 60 \\
\hline
\end{tabular}

TABle 2: Corrosion rate of copper in $1.0 \mathrm{M} \mathrm{Cl}^{-}$solutions in absence or presence of different concentrations of 1-Butyl3-methylimidazolium chloride and 1-Butyl-3-methylimidazolium bromide, $\mathrm{pH} 1.0$.

\begin{tabular}{lcc}
\hline $\begin{array}{l}\text { Concentration of BMIMCl } \\
\text { and BMIMBr }(\mathrm{mM})\end{array}$ & \multicolumn{2}{c}{$k_{r}$ (mm/year) } \\
\hline 0 & BMIMCl & BMIMBr \\
0.1 & 0.417 & 0.417 \\
1.0 & 0.325 & 0.348 \\
5.0 & 0.185 & 0.185 \\
10.0 & 0.116 & 0.139 \\
50.0 & 0.046 & 0.093 \\
\hline
\end{tabular}

are presented in Table 2. The corrosion rate of copper is significantly reduced as a result of the reduction in the $j_{\text {corr }}$. The $k_{r}$ of $\mathrm{Cu}$ in $1.0 \mathrm{M} \mathrm{Cl}^{-}$solution without inhibitors is found to be $0.417 \mathrm{~mm} /$ year, which is $\approx 23$ and 6 times lower in solutions with $50.0 \mathrm{mM}$ 1-Butyl-3-methylimidazolium
TABLE 3: Values of surface coverage $(\Theta)$ of copper in $1.0 \mathrm{M} \mathrm{Cl}^{-}$solutions for different concentrations of 1-Butyl-3-methylimidazolium chloride and 1-Butyl-3-methylimidazolium bromide, $\mathrm{pH}$ 1.0.

\begin{tabular}{lccccc}
\hline Inhibitor & 0.1 & 1.0 & $\begin{array}{c}5.0 \\
(\mathrm{mM})\end{array}$ & 10.0 & 50.0 \\
\hline BMIMCl & 0.22 & 0.56 & 0.72 & 0.89 & 0.96 \\
BMIMBr & 0.17 & 0.56 & 0.67 & 0.78 & 0.83 \\
\hline
\end{tabular}

TABle 4: Slope $(b)$, linear correlation coefficient $\left(R^{2}\right)$, equilibrium constant $(K)$, and standard free energies of adsorption $\left(\Delta G_{\text {ads }}^{0}\right)$ of copper in $1.0 \mathrm{M} \mathrm{Cl}^{-}$solutions for different concentrations of 1-Butyl-3-methylimidazolium chloride and 1-Butyl-3methylimidazolium bromide.

\begin{tabular}{lcccc}
\hline Inhibitor & $b$ & $R^{2}$ & $K\left(\mathrm{M}^{-1}\right)$ & $\Delta G_{\text {ads }}^{0}\left(\mathrm{~kJ} \mathrm{~mol}{ }^{-1}\right)$ \\
\hline BMIMCl & 1.0 & 0.9997 & $1.0 \times 10^{3}$ & -27.2 \\
BMIMBr & 1.1 & 0.9999 & $1.1 \times 10^{3}$ & -27.4 \\
\hline
\end{tabular}

chloride or 1-Butyl-3-methylimidazolium bromide, respectively. Thus, these results reveal the capability especially of $\mathrm{BMIMCl}$ to act as a corrosion protective layer on copper in chloride solutions.

3.2. Chronoamperometric Measurements. The effects of an addition of 1-Butyl-3-methylimidazolium chloride and 1Butyl-3-methylimidazolium bromide to the $\mathrm{Cl}^{-}$electrolyte on the behavior of copper were studied by chronoamperometry. The chronoamperometric curves in Figure 4 were recorded at the electrode potential of $-250,+100$, and $+350 \mathrm{mV}(\mathrm{SCE}(\mathrm{NaCl}))$ in solutions without (curves $(a),(d)$ ) and with $50.0 \mathrm{mM}$ of BMIMCl (curves $(b),(c)$, and $(e)$ ), $\mathrm{pH}$ 1.0. Similar curves were recorded for BMIMBr. The potentials applied to the copper electrode were chosen on basis of polarization curves (Figure 2), and they regarded the cathodic (1b), (1c), and anodic (2a) reactions.

It can be seen that in solutions without inhibitors, curves (a) and (b), a thick film $\mathrm{CuCl}_{\mathrm{ads}}$ was formed on the electrode surface according to the reaction (3). The large current suggests that the layer was not compact. However, the film breakdown or corrosion products inside it are due to the continuous dissolution of copper

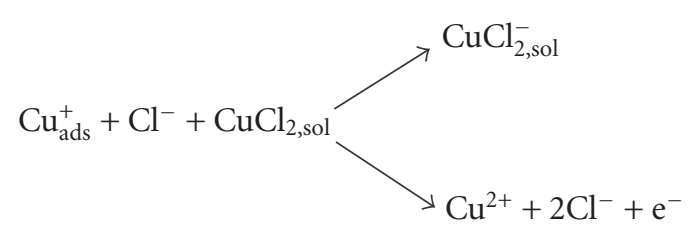

In the presence of $\mathrm{BMIMCl}$ or $\mathrm{BMIMBr}$, the smaller currents for reactions (1b), (1c), and (2a) were recorded, especially for BMIMCl (curves $(b),(c)$, and $(e)$ ). This must be due to the adsorption of BMIMCl or BMIMBr molecules on the copper surface limiting of the aggressive attack on the solutions on the metal. In this case, the protective layer on the copper surface was the most compact for both inhibitors. 
TABLE 5: Quantum chemical parameters for $\mathrm{BMIM}^{+}$calculated by PM3 semiempirical method.

\begin{tabular}{lcccccr}
\hline & \multicolumn{3}{c}{ Net atomic charges } & $E_{\text {HOMO }}(\mathrm{eV})$ & $E_{\mathrm{LUMO}}(\mathrm{eV})$ & $\Delta E(\mathrm{eV})$ \\
$\mathrm{N}_{1}$ & $\mathrm{C}_{2}$ & $\mathrm{~N}_{3}$ & $\mathrm{C}_{4}$ & $\mathrm{C}_{5}$ & & \\
\hline 0.407 & -0.316 & 0.416 & -0.217 & -0.209 & -0.8355 & 0.6844 \\
\hline
\end{tabular}

\subsection{Electrochemical Quartz Crystal Microbalance Measure-} ments. The electrochemical quartz crystal microbalance (EQCM) has been widely used to observe the response of mass loading on the surface. The EQCM technique is based on the piezoelectric effect. The resonant frequency of the quartz crystal lattice vibrations in a thin quartz crystal wafer is measured as a function of the mass attributed to the crystal interfaces $[61,62]$. Sauerbrey's equation is commonly used to describe the linear relationship between the frequency shift $(\Delta f)$ and the mass change $(\Delta m)$. Using the EQCM, the change in surface mass is calculated from the change in resonant frequency according to the equation:

$$
\Delta m=-\frac{\Delta f}{K / S_{p}},
$$

where $K$ is the fundamental constant predicted to be $56.6 \mathrm{~Hz} \mathrm{~cm}^{2} \mu \mathrm{g}$ for quartz crystal with the resonant frequency of ca. $5 \mathrm{MHz}$, and $S_{p}$ is the piezoelectrically active area of the quartz crystal covered by the $\mathrm{Cu}$ film [63]. It is significant that a decrease in frequency corresponds to an increase in surface mass. The mass change is reasonably assumed as the result of metal corrosion as well as the adsorption of components of studied electrolytes.

The influence of 1-Butyl-3-methylimidazolium chloride and 1-Butyl-3-methylimidazolium bromide on corrosion of copper was additionally tested by EQCM measurements. The investigations were carried out in $1.0 \mathrm{M} \mathrm{Cl}^{-}$without and with the addition of BMIMCl or BMIMBr of $50.0 \mathrm{mM}(\mathrm{pH} 1.0)$ in the presence of air. The results are presented in Figure 5. The curves represent the change of mass $(\Delta m)$, calculated from the frequency increase/decrease (8). Similar curves were recorded for BMIMCl. The curve (a) representing the solution without inhibitors shows an increase in the mass of copper electrode from -600 to $+120 \mathrm{mV}(\mathrm{SCE}(\mathrm{NaCl})$ ) (Section 2), which may by attributed to the oxide formation following the reactions

$$
\begin{gathered}
2 \mathrm{Cu}^{+}+\frac{1}{2} \mathrm{O}_{2}+2 \mathrm{e}^{-} \longleftrightarrow \mathrm{Cu}_{2} \mathrm{O}_{\mathrm{ads}} \\
\mathrm{Cu}_{2}^{+}+\frac{1}{2} \mathrm{O}_{2}+2 \mathrm{e}^{-} \longleftrightarrow \mathrm{CuO}_{\mathrm{ads}} .
\end{gathered}
$$

In the range of the potential from +120 to $+400 \mathrm{mV}$, $(\mathrm{SCE}(\mathrm{NaCl}))($ Section 3$)$ was observed to increase, $\Delta m / S_{p}$ of ca. $0.22 \mu \mathrm{g} \mathrm{cm}^{-2}$. However, the copper electrode is partially covered by an oxide film, which dissolves slowly. Simultaneously, the $\mathrm{Cl}^{-}$ions interact with the electrode; therefore, for solutions without inhibitors, $\Delta m$ increased immediately because of the precipitation of $\mathrm{CuCl}_{\text {ads }}$ layer which could be formed on the copper surface according to the reaction (3). This effect was observed in numerous studies. In several investigations [64-69], only low concentration of chloride, in the range from 0.1 to $10.0 \mathrm{mM}$, was used. In other words [70$72]$, much greater chloride concentrations were employed, then the protective layer dissolves and passes into the solutions as the following complexes: $\mathrm{CuCl}_{2}$ and $\mathrm{CuCl}_{3}{ }^{2-}$. It is obvious that those conditions were more favorable to the precipitation of $\mathrm{CuCl}_{\mathrm{ads}}$ layer, which could act as a protective barrier safeguarding copper from its further oxidation. The action of $\mathrm{Cu}_{2} \mathrm{O}_{\mathrm{ads}}, \mathrm{CuO}_{\mathrm{ads}}$, and $\mathrm{CuCl}_{\mathrm{ads}}$ can be physically interpreted as a blockage of the copper surface which after changing direction potential on the opposite completely dissolves.

In the next experiment, 1-Butyl-3-methylimidazolium chloride or 1-Butyl-3-methylimidazolium bromide were added to $1.0 \mathrm{M}$ chloride solutions, see Figure 5 curve $(b)$ which concerns BMIMBr. Similar curve was obtained for $\mathrm{BMIMCl}$. In anodic cycle on the curve $(b)$ appear two characteristics sections of change of mass in the function of potential of electrode. After crossing potential $-600 \mathrm{mV}$ $(\mathrm{SCE}(\mathrm{NaCl}))$, the film on the copper surface was precipitated (Sections 1 and 2). Therefore, it was assumed that BMIMCl or BMIMBr molecules are adsorbed directly on the surface of copper to form monomolecular layers as a complex on the metal surface. It is clear that the inhibitory action of BMIMCl and $\mathrm{BMIMBr}$ reduces the surface area available for oxygen. After crossing potential $+120 \mathrm{mV}(\mathrm{SCE}(\mathrm{NaCl}))$, layer surface BMIMX (where $\mathrm{X}$ is the $\mathrm{Cl}^{-}$or $\mathrm{Br}^{-}$) becomes more tight as a result of the precipitation of the $\mathrm{CuCl}_{\mathrm{ads}}$ and $\mathrm{CuBr}_{\mathrm{ads}}$ layers on the copper surface (Sections 2 and 3). Moreover, after the change of direction of the potential $(+400 \mathrm{mV}$ $(\mathrm{SCE}(\mathrm{NaCl})), \mathrm{CuCl}_{\mathrm{ads}}$ and $\mathrm{CuBr}_{\text {ads }}$ were dissolved. However, $\Delta m$ was slightly changed (curve $(b)$ ). Probably, precipitated layer did not appear on the copper surface. BMIMCl and BMIMBr form adherent layers on the copper surface. This leads to the protection of the $\mathrm{Cu}$ surface from the attack of aggressive solutions and oxygen.

It seems to be obvious that 1-Butyl-3-methylimidazolium chloride or 1-Butyl-3-methylimidazolium bromide molecules are chemisorbed on the surface of copper. Probably the adsorption of BMIMCl and BMIMBr molecules can occur through the formation of copper-nitrogen coordinate bond or the $\pi$-electron interaction between the aromatic ring and the copper substrate.

3.4. Scanning Electron Microscopy Studies. The surface morphology of copper samples immersed in $1.0 \mathrm{M} \mathrm{Cl}^{-}(\mathrm{pH}$ 1.0) for 24 hours in the absence and presence of $50.0 \mathrm{mM}$ of 1-Butyl-3-methylimidazolium chloride or 1-Butyl-3methylimidazolium bromide was studied by scanning electron microscopy (SEM). The solutions were not degassed.

Figure 6 shows the surface morphology of copper specimens (a) before and (b) after being immersed in corrosive solution. Figure 6(b) reveals that the surface was strongly 
damaged in the absence of inhibitors. The presence of chloride ions and dissolved oxygen contributes to the oxidation of the metal. The copper surface is covered by aggregates of small cubic crystals $\mathrm{CuCl}_{\text {ads }}$ and probably $\mathrm{Cu}_{2} \mathrm{O}$ or $\mathrm{CuO}$. Figure 6(c) shows SEM image of the surface of copper specimens after immersion for the same time interval in corrosive solution additionally containing $50.0 \mathrm{mM}$ of BMIMCl. However, in these conditions, the film precipitates on the surface of copper (Figure 6(c)). A similar result was obtained for BMIMBr. The SEM photographs show that it does not cover tightly the surface and hence does not protect the $\mathrm{Cu}$ surface to an adequate degree. Chloride ions, oxygen, and water penetrate the protective film through pores, flaws, or other weak spots what results in further corrosion of copper. The results of the action of aggressive environment were visible after the removal of protective layer from the surface of copper. It well adhered to surface of the metal, and removal of protective film was difficult enough. In this aim, ultrasonic water baths were used. The sample was shaken in diluted sulphuric acid and rinsed in propanol. Figure 6 presents samples after the removal of the inhibiting film which contained (d) 1-Butyl-3-methylimidazolium chloride and (e) 1-Butyl-3-methyl-imidazolium bromide. These results indicated that a more tight protective layer was received for solution with 1-Butyl-3-methylimidazolium chloride (Figure 6(d)). Moreover, the BMIMCl in chloride solution was a better inhibitor than the BMIMBr.

3.5. Adsorption Isotherm. It has been assumed that inhibitor molecules establish their inhibition action via the adsorption of the inhibitor onto the metal surface. The adsorption can be described by two main types of interaction: physical adsorption and chemisorption. The adsorption processes of inhibitors are influenced by the chemical structure of organic compounds, the nature and surface change of metal, the distribution of charge in molecule, and the type of aggressive media.

Assuming the corrosion inhibition was caused by the adsorption of inhibitor on metal surface, the values of surface coverage $(\Theta)$ for different concentrations of inhibitors were calculated on the basis of polarization curves according to the equation:

$$
\Theta=1-\frac{j_{\text {inh }}}{j_{o}} .
$$

The values of the surface coverage are listed in Table 3. It can be seen that the $\Theta$ increased with an increase in the concentration of BMIMCl and BMIMBr. It is also worth noticing that at $50.0 \mathrm{mM}$ solution the inhibitors of the surface coverage are higher for the BMIMCl (Table 3).

Basic information on the interaction between the inhibitors and the metal surface can be provided by the adsorption isotherm. All isotherms can be expressed by

$$
f(\Theta, x) \exp (-2 a \Theta)=K c,
$$

where $f(\Theta, x)$ is the configurational factor which depends upon the physical model and the assumptions underlying the derivation of the isotherm [17], $x$ is the size ratio, $a$ is the molecular interaction parameter, $K$ is the equilibrium constant of the adsorption process, and $c$ is the inhibitor concentration.

Figure 7 shows the dependence of the fraction of the surface covered $c / \Theta$ as a function of the concentration $c$ of 1-Butyl-3-methylimidazolium chloride or 1-Butyl-3methylimidazolium bromide. It should be explained that other adsorption isthoterms (Frumkin and Temkin) were also checked. The linear correlation coefficient was used to choose the isotherm that fits the best of the experimental data. It should be noticed that the data fit the straight line with a slope nearly equal unity with linear correlation coefficient higher than 0.999 (Table 4) indicates that these inhibitors adsorb according to the Langmuir adsorption isotherm $[17,73,74]$ given by the following equation:

$$
\frac{c}{\Theta}=\frac{1}{K}+c,
$$

where $K$ is the adsorption equilibrium constant, related to the free energy of adsorption, $\Delta G_{\text {ads }}^{0}$

$$
K=\frac{1}{c_{\text {solv }}} \exp \left(\frac{-\Delta G_{\mathrm{ads}}^{0}}{\mathrm{RT}}\right),
$$

where $c_{\text {solv }}$ represents molar concentration of the solvent, which in the case of water is $55.5 \mathrm{~mol} \mathrm{dm}^{-3}$. The free energy of adsorption was calculated from the adsorption equilibrium constant using the equation [75]

$$
\Delta G_{\text {ads }}^{0}=-\mathrm{RT} \ln (55.5 K) .
$$

The slopes of linear correlation coefficients, equilibrium constants, and the free energies adsorption of BMIMCl and BMIMBr for copper are presented in Table 4.

The nature of corrosion inhibition has been deduced in terms of the adsorption characteristics of the inhibitor [76]. The metal surface in aqueous solution is always covered with adsorbed water dipoles. Therefore, the adsorption of inhibitor molecules from aqueous solution is a quasisubstitution process, the thermodynamics of which depend on the number of water molecules replaced by the inhibitor molecule. The Langmuir isotherm is based on the assumption that each site of metal surface holds one adsorbed species. This kind of isotherm involves the assumption of no interaction between the adsorbed species on the metal surface. The negative values of $\Delta G_{\mathrm{ads}}^{0}$ (Table 4 ) prove the strong interaction of BMIMCl or BMIMBr molecules on to the copper surface $[58,77]$.

Generally, values $\Delta G_{\text {ads }}^{0}$ around $-20 \mathrm{~kJ} \mathrm{~mol}^{-1}$ or lower are consistent with the electrostatic interaction between the charged molecules and the charged metal surface (physisorption). Those more negative than $-40 \mathrm{~kJ} \mathrm{~mol}^{-1}$ involve charge sharing or transfer from the inhibitor molecules to the metal to form a coordinate type of bond (chemisorption) [78-80]. For investigated ionic liquids inhibitor, it can be concluded that calculated $\Delta G_{\text {ads }}^{0}$ values equal -27.2 and $-27.4 \mathrm{~kJ} \mathrm{~mol}^{-1}$ for BMIMCl and BMIMBr, respectively (Table 4). However, the free energies of adsorption are situated in range from -20 to $-40 \mathrm{~kJ} \mathrm{~mol}^{-1}$; therefore, it can be accepted with 
a large probability, that the adsorption mechanisms of $\mathrm{BMIMCl}$ and $\mathrm{BMIMBr}$ in $1.0 \mathrm{M} \mathrm{Cl}^{-}$solution involve first of all chemical adsorption on the copper surface with negligible participation physisorption.

The adsorption of the inhibitor on the metal surface is the first step in the action mechanism of inhibitors in aggressive acid media.The adsorption of 1-Butyl-3-methylimidazolium chloride or 1-Butyl-3-methylimidazolium bromide on the copper surface makes a barrier for mass and charge transfers. This situation leads to the protection of the copper surface from the attack of aggressive solutions. The orientation of the BMIMX molecules in the adsorbed state on the copper surface could be resolved by the application of quantum chemical calculations.

3.6. Quantum Chemical Calculations. Quantum chemical calculations have been widely used to study the reaction mechanisms and to interpret the experimental results as well as to solve chemical ambiguities. The structure and electronic parameters can be obtained by means of theoretical calculations using the computational methodologies of quantum chemistry [81]. The geometry of the inhibitor in its ground state as well as the nature of their molecular orbitals, highest occupied molecular orbital (HOMO) and lowest unoccupied molecular orbital (LUMO), are involved in the properties of the activity of inhibitors. The HOMO is the orbital that could act as an electron donor, since it is the outermost orbital containing electrons. The LUMO is the orbital that could act as the electron acceptor, since it is the innermost orbital which has place to accept electrons. Highest occupied molecular orbital energy $\left(E_{\mathrm{HOMO}}\right)$ and lowest unoccupied molecular orbital energy ( $\left.E_{\mathrm{LUMO}}\right)$ are very popular quantum chemical parameters. These orbitals, also called the frontier orbitals, determine the way the molecule interacts with other species. It should be noted that the $E_{\mathrm{HOMO}}$ is often associated with the electron donating ability of the molecule, whereas $E_{\text {LUMO }}$ indicates its ability to accept electrons. The energy of the HOMO is directly related to the ionization potential, and the energy of the LUMO is directly related to the electron affinity. The calculated difference $\left(\Delta E=E_{\mathrm{LUMO}}-\right.$ $\left.E_{\text {HOMO }}\right)$ demonstrates inherent electron donating ability and measures the interaction of the inhibitor molecules with metal surface. A large energy gap $(\Delta E)$ implies high stability for the molecule in chemical reactions [82].

In current practice semiempirical methods serve as efficient computational tools which can yield fast quantitative estimates for a number of properties. The PM3 is semiempirical method based on the neglected differential diatomic overlap integral approximation. However, the PM3 method uses the same formalism and equations as the AM1 method [83].

The quantum chemical parameters for $\mathrm{MBIM}^{+}$were obtained by PM3 method and listed in Table 5. Moreover, Figure 8 shows the molecular structure of 1-Butyl-3methylimidazolium ion, the charge density distribution $(\delta)$ for nitrogen and carbon atoms, and molecular orbital density distribution, highest occupied molecular orbital (HOMO) and lowest unoccupied molecular orbital (LUMO). The binding capability of a molecule with metal depends also on the electronic charge on the chelating atom. From the data on the electron density of $\mathrm{BMIM}^{+}$, it can be concluded that

(i) the largest positive charge $\left(\delta^{+}\right)$is localized at the $\mathrm{N}_{1}$ and $\mathrm{N}_{3}$ atoms;

(ii) the negative charge $\left(\delta^{-}\right)$localized at the $\mathrm{C}_{4}, \mathrm{C}_{3}$, and $\mathrm{C}_{5}$ atoms. However, the $\delta_{\mathrm{C}_{5}}^{-}$charge is smaller than $\delta_{\mathrm{C}_{4}}^{-}$ and $\delta_{\mathrm{C}_{2}}^{-}$;

(iii) the $\mathrm{BMIM}^{+}$interacts perhaps with the surface $\mathrm{Cu}$ electrode loaded negatively with nitrogen atoms and positively with carbon atoms. It is obvious that the interaction with the surface of the electrode is stronger through nitrogen atoms.

The higher the $E_{\text {HOMO }}$ (Table 5) of the inhibitor, the greater the tendency of offering electrons to unoccupied $d$ orbital of the $\mathrm{Cu}$ and the higher the corrosion inhibition efficiency for copper in $\mathrm{Cl}^{-}$acid solutions (Figure 3 ). In addition, the higher the $E_{\mathrm{LUMO}}$, the more difficult the acceptance of electron from the metal surface. However, the LUMO-HOMO energy gap admits low values, what is effective with this is that the inhibition efficiency of inhibitors was improved. Figure 8 shows that the highest occupied molecular orbital (HOMO) is mainly constituted by $\mathrm{N}_{1}$ and $\mathrm{N}_{3}$ atoms, and the lowest unoccupied molecular orbital (LUMO) is constituted by $\mathrm{C}_{2}, \mathrm{C}_{4}$, and $\mathrm{C}_{5}$ atoms, which indicate that $\mathrm{N}_{1}$ and $\mathrm{N}_{3}$ can provide electrons, and $\mathrm{C}_{2}, \mathrm{C}_{4}$, and $\mathrm{C}_{5}$ can accept electrons.

Four types of adsorption may take place involving BMIMX molecules on the copper-solution interface:

(i) electrostatic attraction between charged molecules and the charged metal,

(ii) interaction of unshared electron pairs in the molecule with the metal,

(iii) interaction of $\pi$-electrons with the metal,

(iv) a combination of the above.

Frontier orbital electron densities on atoms provide a useful means for the detailed characterization of donoracceptor interactions. Figure 9 shows schematic illustration of mechanism of corrosion protection of copper by $\mathrm{BMIMCl}$ or BMIMBr. The mechanism involves the formation of protective monolayer inhibitors which protect copper before corrosion.

\section{Conclusion}

The following results can be drawn from this study:

(1) the investigated ionic liquids (ILs): 1-Butyl-3-methylimidazolium chloride (BMIMCl) and 1-Butyl3-methylimidazolium bromide (BMIMBr) exhibit inhibiting properties for the corrosion of copper in 1.0 $\mathrm{M} \mathrm{Cl}^{-}$solutions of $\mathrm{pH} 1.0$,

(2) the inhibition efficiency increased with the increase in ILs concentration, followed the order: $\mathrm{BMIMCl}>$ BMIMBr; 
(3) the adsorption of the investigated compounds was confirmed to follow the Langmuir adsorption isotherm;

(4) the values of standard free energies of adsorption suggest mainly the chemical adsorption of BMIMCl and $\mathrm{BMIMBr}$ on the copper surface;

(5) the quantum chemistry calculation results show that the imidazoline ring and heteroatoms are the active sites of the both inhibitors;

(6) the inhibition effect is due to the formation of an insoluble stable film through the process of adsorption of the inhibitor molecules on the copper surface.

\section{Acknowledgments}

One of the authors would like to thank Professor M. Hepel from the Department of Chemistry SUNY at Potsdam, USA, A. Skrobisz, and his wife Heni for helpful discussions and a critical reading of the paper.

\section{References}

[1] D. Kuron, H. J. Rother, and H. Graefen, "Inhibition of aqueous and alcoholic-aqueous heat-carriers," Werkstoffe und Korrosion, vol. 32, no. 10, pp. 409-421, 1981.

[2] N. Huynh, S. E. Bottle, T. Notoya, and D. P. Schweinsberg, "Inhibitive action of the octyl esters of 4- and 5carboxybenzotriazole for copper corrosion in sulphate solutions," Corrosion Science, vol. 42, no. 2, pp. 259-274, 2000.

[3] D. Gopi and S. Rajeswari, "Surface characterization and electrochemical corrosion behaviour of 304 stainless steel in aqueous media," Journal of Solid State Electrochemistry, vol. 6, no. 3, pp. 194-202, 2002.

[4] B. Trachli, M. Keddam, H. Takenouti, and A. Srhiri, "Protective effect of electropolymerized 3-amino 1,2,4-triazole towards corrosion of copper in $0.5 \mathrm{M} \mathrm{NaCl}$," Corrosion Science, vol. 44, no. 5, pp. 997-1008, 2002.

[5] M. Ohsawa and W. Suëtaka, "Spectro-electrochemical studies of the corrosion inhibition of copper by mercaptobenzothiazole," Corrosion Science, vol. 19, no. 7, pp. 709-722, 1979.

[6] G. W. Walter, "A review of impedance plot methods used for corrosion performance analysis of painted metals," Corrosion Science, vol. 26, no. 9, pp. 681-703, 1986.

[7] B. Trachli, M. Keddam, H. Takenouti, and A. Srhiri, "Protective effect of electropolymerized 3-amino 1,2,4-triazole towards corrosion of copper in $0.5 \mathrm{M} \mathrm{NaCl}$," Corrosion Science, vol. 44, no. 5, pp. 997-1008, 2002.

[8] M. Hepel and M. Scendo, "Growth kinetics of multi-layer CuEtX films on copper piezoelectrodes," in Thin Films: Preparation, Characterization, Applications, M. P. Soriaga, J. Stickney, L. A. Bottomley, and Y.-G. Kim, Eds., Kluwer Academic/Plenum Publishers, New York, NY, USA, 2001.

[9] M. Hepel and M. Scendo, "Kinetics of CuEtX film formation on copper piezoelectrodes," Journal of Electroanalytical Chemistry, vol. 538-539, pp. 121-132, 2002.

[10] M. Scendo, "Potassium ethyl xanthate as corrosion inhibitor for copper in acidic chloride solutions," Corrosion Science, vol. 47, no. 7, pp. 1738-1749, 2005.
[11] M. Scendo, "Corrosion inhibition of copper by potassium ethyl xanthate in acidic chloride solutions," Corrosion Science, vol. 47, no. 11, pp. 2778-2791, 2005.

[12] M. Scendo, D. Poddebniak, and J. Malyszko, "Indole and 5chloroindole as inhibitors of anodic dissolution and cathodic deposition of copper in acidic chloride solutions," Journal of Applied Electrochemistry, vol. 33, no. 3-4, pp. 287-293, 2003.

[13] A. A. Aksüt and S. Bilgiç, "The effect of amino acids on the corrosion of nickel in $\mathrm{H}_{2} \mathrm{SO}_{4}$," Corrosion Science, vol. 33, no. 3, pp. 379-387, 1992.

[14] H. Baba and T. Kodama, "Corrosion inhibition and characteristics of the triazinedithiol surface film on copper under potentiostatic anodization," Corrosion Science, vol. 41, no. 10, pp. 1987-2000, 1999.

[15] G. Moretti and F. Guidi, "Tryptophan as copper corrosion inhibitor in $0.5 \mathrm{M}$ aerated sulfuric acid," Corrosion Science, vol. 44, no. 9, pp. 1995-2011, 2002.

[16] J. B. Matos, L. P. Pereira, S. M. L. Agostinho, O. E. Barcia, G. G. O. Cordeiro, and E. D'Elia, "Effect of cysteine on the anodic dissolution of copper in sulfuric acid medium," Journal of Electroanalytical Chemistry, vol. 570, no. 1, pp. 91-94, 2004.

[17] M. Scendo, "The effect of purine on the corrosion of copper in chloride solutions," Corrosion Science, vol. 49, no. 2, pp. 373390, 2007.

[18] M. Scendo, "The influence of adenine on corrosion of copper in chloride solutions," Corrosion Science, vol. 50, no. 7, pp. 2070-2077, 2008.

[19] M. Scendo, "Inhibitive action of the purine and adenine for copper corrosion in sulphate solutions," Corrosion Science, vol. 49, no. 7, pp. 2985-3000, 2007.

[20] M. Scendo, "Inhibition of copper corrosion in sodium nitrate solutions with nontoxic inhibitors," Corrosion Science, vol. 50, no. 6, pp. 1584-1592, 2008.

[21] H. Zhao, "Innovative applications of ionic liquids as "green" engineering liquids," Chemical Engineering Communications, vol. 193, no. 12, pp. 1660-1677, 2006.

[22] S. Zhang, N. Sun, X. He, X. Lu, and X. Zhang, "Physical properties of ionic liquids: database and evaluation," Journal of Physical and Chemical Reference Data, vol. 35, no. 4, pp. 14751517, 2006.

[23] A. Fernicola, B. Scrosati, and H. Ohno, "Potentialities of ionic liquids as new electrolyte media in advanced electrochemical devices," Ionics, vol. 12, no. 2, pp. 95-102, 2006.

[24] T. Tsuda and C. L. Hussey, "Electrochemical applications of room-temperature ionic liquids," Electrochemical Society Interface, vol. 16, no. 1, pp. 42-49, 2007.

[25] S. Muralidharan and S. Venkatakrishna Iyer, "The influence of N-heterocyclics on corrosion inhibition and hydrogen permeation through mild steel in acidic solutions," AntiCorrosion Methods and Materials, vol. 44, no. 2, pp. 100-106, 1997.

[26] R. Gašparac, C. R. Martin, and E. Stupnišek-Lisac, "In situ studies of imidazole and its derivatives as copper corrosion inhibitors I. Activation energies and thermodynamics of adsorption," Journal of the Electrochemical Society, vol. 147, no. 2, pp. 548-551, 2000.

[27] D. Q. Zhang, L. X. Gao, and G. D. Zhou, "Inhibition of copper corrosion in aerated hydrochloric acid solution by heterocyclic compounds containing a mercapto group," Corrosion Science, vol. 46, no. 12, pp. 3031-3040, 2004.

[28] M. A. Quraishi, M. Z. A. Rafiquee, S. Khan, and N. Saxena, "Corrosion inhibition of aluminium in acid solutions by some imidazoline derivatives," Journal of Applied Electrochemistry, vol. 37, no. 10, pp. 1153-1162, 2007. 
[29] S. Caporali, A. Fossati, A. Lavacchi, I. Perissi, A. Tolstogouzov, and U. Bardi, "Aluminium electroplated from ionic liquids as protective coating against steel corrosion," Corrosion Science, vol. 50, no. 2, pp. 534-539, 2008.

[30] G. Yue, X. Lu, Y. Zhu, X. Zhang, and S. Zhang, "Surface morphology, crystal structure and orientation of aluminium coatings electrodeposited on mild steel in ionic liquid," Chemical Engineering Journal, vol. 147, no. 1, pp. 79-86, 2009.

[31] A. Inglese, P. D’Angelo, R. De Lisi, and S. Milioto, "Surface tension, heat capacity, and volume of amphiphilic compounds in formamide solutions," Journal of Solution Chemistry, vol. 27, no. 5, pp. 403-424, 1998.

[32] P. Zhao, C. Zhong, L. Hunag, L. Niu, and F. Zhang, "Corrosion inhibition of dibenzo $[1,4,8,11]$ tetraaza [14] annulene nickel on steel in $1 \mathrm{M} \mathrm{HCl,"} \mathrm{Corrosion} \mathrm{Science,} \mathrm{vol.} \mathrm{50,} \mathrm{no.} \mathrm{8,} \mathrm{pp.}$ 2166-2171, 2008.

[33] N. Kimizuka and T. Nakashima, "Spontaneous self-assembly of glycolipid bilayer membranes in sugar-philic ionic liquids and formation of ionogels," Langmuir, vol. 17, no. 22, pp. 6759-6761, 2001.

[34] L. C. Branco, J. N. Rosa, J. J. M. Ramos, and C. A. M. Afonso, "Preparation and characterization of new room temperature ionic liquids," Chemistry, vol. 8, no. 16, pp. 3671-3677, 2002.

[35] J. Pernak, K. Sobaszkiewicz, and J. Foksowicz-Flaczyk, "Ionic liquids with symmetrical dialkoxymethyl-substituted imidazolium cations," Chemistry, vol. 10, no. 14, pp. 3479-3485, 2004.

[36] Z. B. Zhou, H. Matsumoto, and K. Tatsumi, "Low-melting, low-viscous, hydrophobic ionic liquids: 1-alkyl(alkyl ether)3-methylimidazolium perfluoroalkyltrifluoroborate," Chemistry, vol. 10, no. 24, pp. 6581-6591, 2004.

[37] Q. Liu, M. H. A. Janssen, F. Van Rantwijk, and R. A. Sheldon, "Room-temperature ionic liquids that dissolve carbohydrates in high concentrations," Green Chemistry, vol. 7, no. 1, pp. 3942, 2005.

[38] W. A. Henderson, V. G. Young Jr., D. M. Fox, H. C. De Long, and P. C. Trulove, "Alkyl vs. alkoxy chains on ionic liquid cations," Chemical Communications, no. 35, pp. 3708-3710, 2006.

[39] Z. Fei, W. H. Ang, D. Zhao et al., "Revisiting ether-derivatized imidazolium-based ionic liquids," Journal of Physical Chemistry B, vol. 111, no. 34, pp. 10095-10108, 2007.

[40] S. Shi, P. Yi, C. Cao, X. Wang, J. Su, and J. Liu, "Synthesis of new ionic liquids and corrosion inhibition performance of its cationic imidazoline group," Journal of Chemical Industry and Engineering (China), vol. 56, no. 6, pp. 1112-1119, 2005.

[41] J. Malyszko and M. Scendo, "Redox equilibria in the $\mathrm{Cu}-\mathrm{Cu}-$ $\mathrm{Cu}$ system in water-dimethylsulphoxide (DMSO) mixtures," Monatshefte für Chemie, vol. 118, no. 4, pp. 435-443, 1987.

[42] J. Matyszko and M. Scendo, "The stepwise reduction of $\mathrm{Cu}$ (II) at a platinum electrode in water $+\mathrm{N}, \mathrm{N}$-dimethylformamide mixtures," Journal of Electroanalytical Chemistry, vol. 269, no. 1, pp. 113-128, 1989.

[43] J. Małyszko and M. Scendo, "Electrode kinetics of the $\mathrm{Cu}(\mathrm{II}) / \mathrm{Cu}(\mathrm{I})$ system at platinum in water + dimethylsulphoxide (DMSO) mixtures," Journal of Electroanalytical Chemistry, vol. 250, no. 1, pp. 61-72, 1988.

[44] M. Scendo and J. Malyszko, "Influence of benzotriazole and tolyltriazole on the copper electrodeposition on polycrystalline platinum from acidic chloride solutions," Journal of the Electrochemical Society, vol. 147, no. 5, pp. 1758-1762, 2000.

[45] D. W. Suggs and A. J. Bard, "Scanning tunneling microscopic study with atomic resolution of the dissolution of $\mathrm{Cu}(100)$ electrodes in aqueous chloride media," Journal of Physical Chemistry, vol. 99, no. 20, pp. 8349-8355, 1995.

[46] G. M. Brisard, E. Zenati, H. A. Gasteiger, N. M. Marković, and P. N. Ross, "Underpotential deposition of lead on $\mathrm{Cu}(100)$ in the presence of chloride: ex-situ low-energy electron diffraction, auger electron spectroscopy, and electrochemical studies," Langmuir, vol. 13, no. 8, pp. 2390-2397, 1997.

[47] G. Brisard, N. Bertrand, P. N. Ross, and N. M. Marković, "Oxygen reduction and hydrogen evolution-oxidation reactions on $\mathrm{Cu}(\mathrm{hkl})$ surfaces," Journal of Electroanalytical Chemistry, vol. 480, no. 1-2, pp. 219-224, 2000.

[48] H. Ma, S. Chen, B. Yin, S. Zhao, and X. Liu, "Impedance spectrospic study of corrosion inhibition of copper by surfactants in the acidic solutions," Corrosion Science, vol. 45, no. 5, pp. 867-882, 2003.

[49] D.-Q. Zhang, L.-X. Gao, G.-D. Zhou, and K. Y. Lee, "Undecyl substitution in imidazole and its action on corrosion inhibition of copper in aerated acidic chloride media," Journal of Applied Electrochemistry, vol. 38, no. 1, pp. 71-76, 2008.

[50] E. Yeager, "Electrocatalysts for O reduction," Electrochimica Acta, vol. 29, no. 11, pp. 1527-1537, 1984.

[51] D. Pletcher and S. Sotiropoulos, "A study of cathodic oxygen reduction at platinum using microelectrodes," Journal of Electroanalytical Chemistry, vol. 356, no. 1-2, pp. 109-119, 1993.

[52] A. H. Moreira, A. V. Benedetti, P. L. Cabot, and P. T. A. Sumodjo, "Electrochemical behaviour of copper electrode in concentrated sulfuric acid solutions," Electrochimica Acta, vol. 38, no. 7, pp. 981-987, 1993.

[53] H. P. Lee and K. Nobe, "Kinetics and mechanisms of $\mathrm{Cu}$ electrodissolution in chloride media," Journal of the Electrochemical Society, vol. 133, no. 10, pp. 2035-2043, 1986.

[54] F. K. Crundwell, "The anodic dissolution of copper in hydrochloric acid solutions," Electrochimica Acta, vol. 37, no. 15, pp. 2707-2714, 1992.

[55] M. A. Migahed, "Electrochemical investigation of the corrosion behaviour of mild steel in $2 \mathrm{M} \mathrm{HCl}$ solution in presence of 1-dodecyl-4-methoxy pyridinium bromide," Materials Chemistry and Physics, vol. 93, no. 1, pp. 48-53, 2005.

[56] H. Ashassi-Sorkhabi and M. Es'haghi, "Corrosion inhibition of mild steel in acidic media by [BMIm]Br Ionic liquid," Materials Chemistry and Physics, vol. 114, no. 1, pp. 267-271, 2009.

[57] S. S. Abd El Rehim, M. A. M. Ibrahim, and K. F. Khalid, "The inhibition of 4-(2'-amino-5'-methylphenylazo) antipyrine on corrosion of mild steel in $\mathrm{HCl}$ solution," Materials Chemistry and Physics, vol. 70, no. 3, pp. 268-273, 2001.

[58] M. Elachouri, M. S. Hajji, M. Salem et al., "Some nonionic surfactants as inhibitors of the corrosion of iron in acid chloride solutions," Corrosion, vol. 52, no. 2, pp. 103-108, 1996.

[59] B. R. Babu and R. Holze, "Corrosion and hydrogen permeation inhibition for mild steel in $\mathrm{HCl}$ by isomers of organic compounds," British Corrosion Journal, vol. 35, no. 3, pp. 204209, 2000.

[60] V. Shinde, S. R. Sainkar, and P. P. Patil, "Corrosion protective poly(o-toluidine) coatings on copper," Corrosion Science, vol. 47, no. 6, pp. 1352-1369, 2005.

[61] D. Jope, J. Sell, H. W. Pickering, and K. G. Weil, "Application of a quartz crystal microbalance to the study of copper corrosion in acid solution inhibited by triazole-iodide protective films," Journal of the Electrochemical Society, vol. 142, no. 7, pp. 2170 2173, 1995. 
[62] A. R. Hillman, M. J. Swann, and S. Bruckenstein, "General approach to the interpretation of electrochemical quartz crystal microbalance data. 1. Cyclic voltammetry: kinetic subtleties in the electrochemical doping of polybithiophene films," Journal of Physical Chemistry, vol. 95, no. 8, pp. 32713277, 1991.

[63] P. G. Fox, G. Lewis, and P. J. Boden, "Some chemical aspects of the corrosion inhibition of copper by benztriazole," Corrosion Science, vol. 19, no. 7, pp. 457-467, 1979.

[64] R. Michaelis, M. S. Zei, R. S. Zhai, and D. M. Kolb, “The effect of halides on the structure of copper underpotential-deposited onto Pt(111): a low-energy electron diffraction and X-ray photoelectron spectroscopy study," Journal of Electroanalytical Chemistry, vol. 339, no. 1-2, pp. 299-310, 1992.

[65] N. Markovic and P. N. Ross, "Effect of anions on the underpotential deposition of $\mathrm{Cu}$ on $\mathrm{Pt}(111)$ and $\mathrm{Pt}(100)$ surfaces," Langmuir, vol. 9, no. 2, pp. 580-590, 1993.

[66] H. S. Yee and H. D. Abruña, "In situ X-ray absorption spectroscopy studies of copper underpotentially deposited in the absence and presence of chloride on platinum(111)," Langmuir, vol. 9, no. 9, pp. 2460-2469, 1993.

[67] H. Matsumoto, J. Inukai, and M. Ito, "Structures of copper and halides on $\mathrm{Pt}(111), \mathrm{Pt}(100)$ and $\mathrm{Au}(111)$ electrode surfaces studied by in-situ scanning tunneling microscopy," Journal of Electroanalytical Chemistry, vol. 379, no. 1-2, pp. 223-231, 1994.

[68] N. M. Marković, H. A. Gasteiger, and P. N. Ross, "Copper electrodeposition on $\mathrm{Pt}(111)$ in the presence of chloride and (Bi)sulfate: rotating ring- $\mathrm{Pt}(111)$ disk electrode studies," Langmuir, vol. 11, no. 10, pp. 4098-4108, 1995.

[69] N. M. Marković, H. A. Gasteiger, C. A. Lucas, I. M. Tidswell, and P. N. Ross, "The effect of chloride on the underpotential deposition of copper on $\mathrm{Pt}(111)$ : AES, LEED, RRDE, and Xray scattering studies," Surface Science, vol. 335, no. C, pp. 91$100,1995$.

[70] A. Moreau, "Etude du mecanisme d'oxydo-reduction du cuivre dans les solutions chlorurees acides-II. Systemes $\mathrm{CuCu}$ $\mathrm{ClCuCl}$ et $\mathrm{CuCu}(\mathrm{OH}) \mathrm{ClCuClCu}$," Electrochimica Acta, vol. 26, no. 11, pp. 1609-1616, 1981.

[71] M. Itagaki, M. Tagaki, and K. Watanabe, "Study of dissolution mechanisms of copper in perchloric acid solution containing $\mathrm{NaCl}$ by channel flow double electrode and electrochemical quartz crystal microbalance," Corrosion Science, vol. 38, no. 7, pp. 1109-1125, 1996.

[72] M. E. Vela, G. Andreasen, S. G. Aziz, R. C. Salvarezza, and A. J. Arvia, "Sequential in situ STM imaging of electrodissolving copper in different aqueous acid solutions," Electrochimica Acta, vol. 43, no. 1-2, pp. 3-12, 1998.

[73] G. N. Mu, T. P. Zhao, M. Liu, and T. Gu, "Effect of metallic cations on corrosion inhibition of an anionic surfactant for mild steel," Corrosion, vol. 52, no. 11, pp. 853-856, 1996.

[74] F. Bentiss, M. Lagrenée, B. Elmehdi, B. Mernari, M. Traisnel, and H. Vezin, "Electrochemical and quantum chemical studies of 3,5-Di (n-Tolyl)-4-amino-1,2,4-triazole adsorption on mild steel in acidic media," Corrosion, vol. 58, no. 5, pp. 399-407, 2002.

[75] E. Khamis, F. Bellucci, R. M. Latanision, and E. S. H. El-Ashry, "Acid corrosion inhibition of nickel by 2(triphenosphoranylidene) succinic anhydride," Corrosion, vol. 47, no. 9, pp. 677-686, 1991.

[76] H. B. Rudresh and S. M. Mayanna, "Adsorption of ndecylamine on zinc from acidic chloride solution," Journal of the Electrochemical Society, vol. 124, no. 3, pp. 340-342, 1977.
[77] B. V. Savithri and S. M. Mayanna, "Tetrabutyl ammonium iodide, cetyl pyridinium bromide and cetyl trimethyl ammonium bromide as corrosion inhibitors for mild steel in sulphuric acid," Indian Journal of Chemical Technology, vol. 3, no. 5, pp. 256-258, 1996.

[78] F. Bensajjay, S. Alehyen, M. El Achouri, and S. Kertit, "Corrosion inhibition of steel by 1-phenyl 5-mercapto 1,2,3,4tetrazole in acidic environments (0.5 M HSO and $1 / 3 \mathrm{M}$ HPO)," Anti-Corrosion Methods and Materials, vol. 50, no. 6, pp. 402-409, 2003.

[79] F. Bentiss, M. Lebrini, and M. Lagrenée, “Thermodynamic characterization of metal dissolution and inhibitor adsorption processes in mild steel/2,5-bis(n-thienyl)-1,3,4-thiadiazoles/ hydrochloric acid system," Corrosion Science, vol. 47, no. 12, pp. 2915-2931, 2005.

[80] W. H. Li, Q. He, S. T. Zhang, C. L. Pei, and B. R. Hou, "Some new triazole derivatives as inhibitors for mild steel corrosion in acidic medium," Journal of Applied Electrochemistry, vol. 38, no. 3, pp. 289-295, 2008.

[81] F. B. Growcock, "Inhibition of steel corrosion in $\mathrm{HCl}$ by derivatives of cinnamaldehyde. Part I. Corrosion inhibition model," Corrosion, vol. 45, no. 12, pp. 1003-1007, 1989.

[82] Z. Zhou and R. G. Parr, "Activation hardness: new index for describing the orientation of electrophilic aromatic substitution," Journal of the American Chemical Society, vol. 112, no. 15, pp. 5720-5724, 1990.

[83] G. Gece, "The use of quantum chemical methods in corrosion inhibitor studies," Corrosion Science, vol. 50, no. 11, pp. 29812992, 2008. 

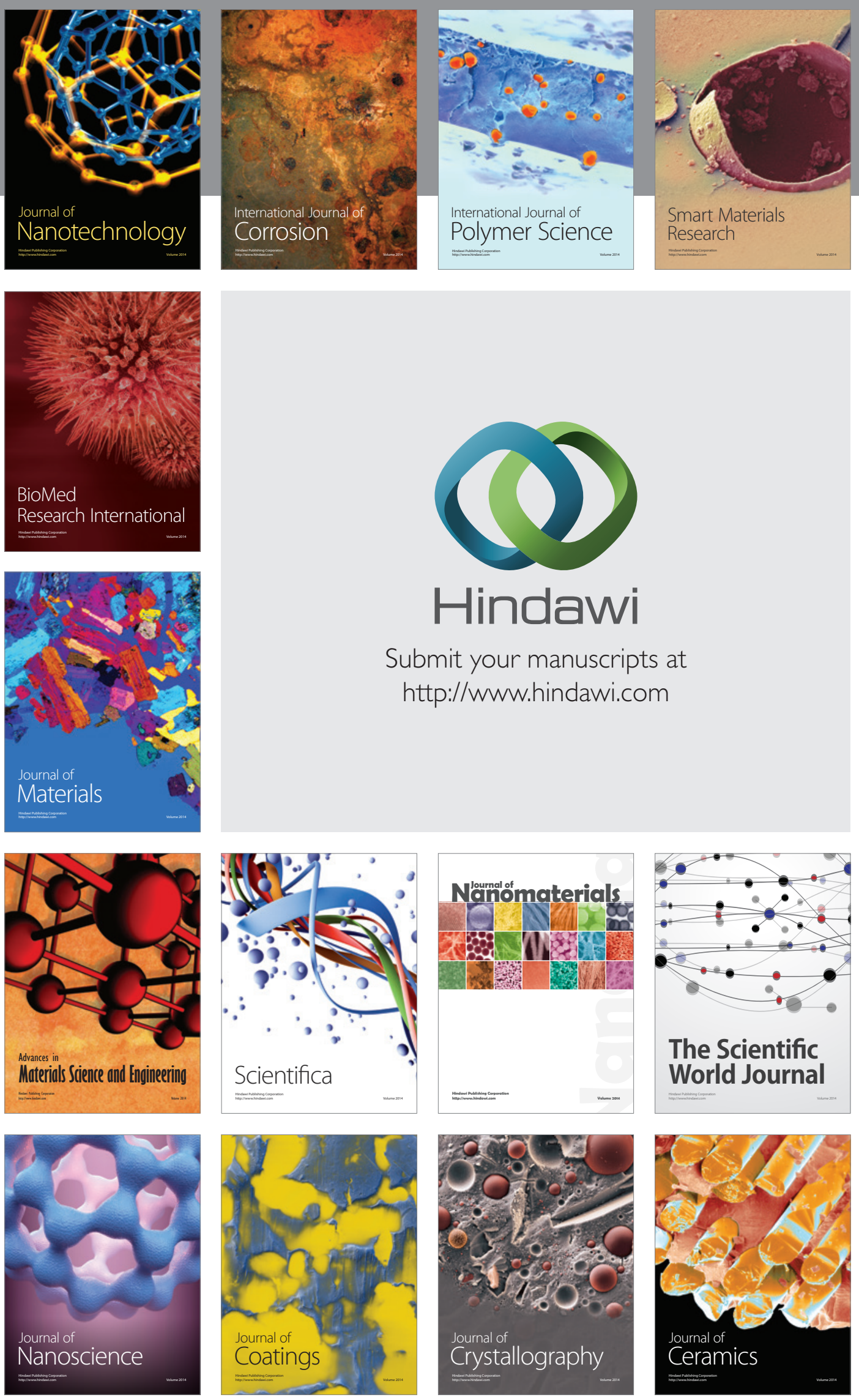

The Scientific World Journal

Submit your manuscripts at

http://www.hindawi.com

\section{World Journal}

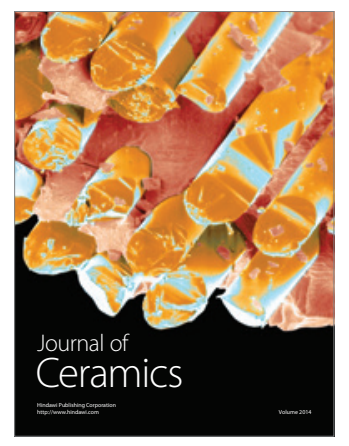

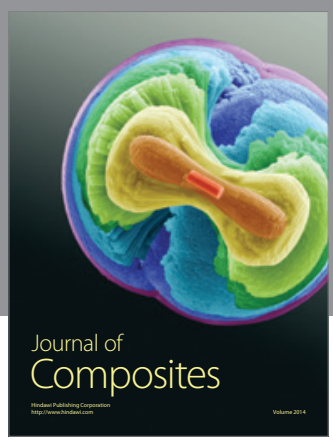
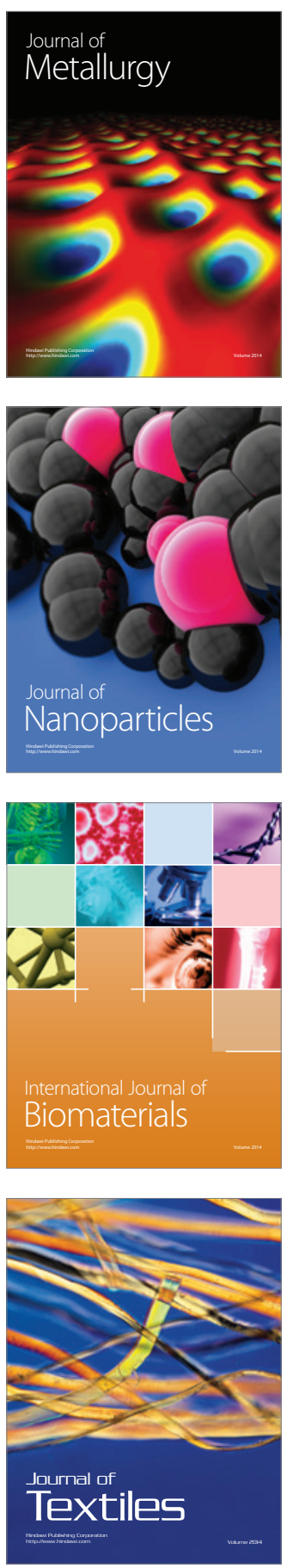